\title{
Dose-finding study on adjuvant chemotherapy with S-1 plus oxaliplatin for gastric cancer
}

\author{
LIN YANG $^{1 *}$, YI YANG ${ }^{2 *}$, QIONG QIN ${ }^{1}$, AIPING ZHOU ${ }^{1}$, JIANJUN ZHAO ${ }^{1}$, \\ JINWAN WANG ${ }^{1}$, CHANG SHU $^{2}$, XINGHUA YUAN ${ }^{1}$ and SONGNIAN HU ${ }^{2}$ \\ ${ }^{1}$ Cancer Institute and Hospital, Chinese Academy of Medical Sciences, Beijing 100021; \\ ${ }^{2}$ Beijing Institute of Genomics, Chinese Academy of Sciences, Beijing 100101, P.R. China
}

Received June 20, 2013; Accepted September 11, 2013

DOI: $10.3892 / \mathrm{mco} .2013 .191$

\begin{abstract}
Gastric cancer (GC) is the fourth most common type of cancer, accounting for an estimated one million new cases annually worldwide. Locally advanced GC often recurs, even following curative surgical resection. Therefore, there is a need for an effective adjuvant chemotherapy regimen. The aim of this trial was to investigate the maximum tolerated dose (MTD) of S-1 when administered in combination with oxaliplatin in postoperative GC patients. Oxaliplatin was administered at a fixed dose of $130 \mathrm{mg} / \mathrm{m}^{2}$ on day 1 . S-1 was administered from day 1 to 14 of a 3 -week cycle and escalated by $10 \mathrm{mg} / \mathrm{m}^{2} /$ day from 60 to $80 \mathrm{mg} / \mathrm{m}^{2} /$ day. A total of 15 patients were enrolled in this study. No dose-limiting toxicities (DLTs) occurred at level $1\left(\mathrm{~S}-1,60 \mathrm{mg} / \mathrm{m}^{2} ; \mathrm{n}=3\right)$. One case of DLT (grade 3 vomiting) occurred at level $2\left(\mathrm{~S}-1,70 \mathrm{mg} / \mathrm{m}^{2} ; \mathrm{n}=6\right)$, whereas 2 cases of grade 3 vomiting were observed at level 3 $\left(\mathrm{S}-1,80 \mathrm{mg} / \mathrm{m}^{2} ; \mathrm{n}=6\right)$. Based on these results, the MTD of S-1 was initially determined to be $70 \mathrm{mg} / \mathrm{m}^{2}$. Furthermore, we observed that cytochrome P450 2A6 (CYP2A6) 41349640C $>$ G was associated with severe neutropenia $(\mathrm{C} / \mathrm{C}$ vs. $\mathrm{C} / \mathrm{G}$ vs. $\mathrm{G} / \mathrm{G}$ $=0$ vs. 33.33 vs. $100 \% ; P=0.03297$, Fisher's exact test) during the entire course of the treatment.
\end{abstract}

\section{Introduction}

Gastric cancer (GC) is the fourth most common type of cancer, accounting for an estimated one million new cases

Correspondence to: Dr Lin Yang, Cancer Institute and Hospital, Chinese Academy of Medical Sciences, 17 Panjiayuan Nanli, Chaoyang District, Beijing 100021, P.R. China

E-mail: yanglin@csco.org.cn

Dr Songnian Hu, Beijing Institute of Genomics, Chinese Academy of Sciences, 1 Beichen West Road, Chaoyang District, Beijing 100101, P.R. China

E-mail: husn@big.ac.cn

*Contributed equally

Key words: S-1, oxaliplatin, adjuvant chemotherapy, maximumtolerated dose, cytochrome P450 2A6 annually worldwide (1). GC is more prevalent in East Asia compared with other countries, with $~ 50 \%$ of the new GC cases occurring in East Asia, including $41 \%$ in China and $11 \%$ in Japan (2). The primary treatment for GC is surgery; however, locally advanced (stage II-III) GC often recurs, even after curative surgical resection $(3,4)$. Therefore, it is crucial to develop adjuvant chemotherapy regimens that may improve survival in GC patients following surgical resection.

S-1, an oral anticancer agent combining tegafur (FT), 5-chloro-2,4-dihydroxipyridine (CDHP) and potassium oxonate (Oxo) in a molar ratio of 1:0.4:1, has shown clinical efficacy in patients diagnosed with GC (5-7). The ACTS-GC trial demonstrated that S-1 improved the 5-year overall survival (OS) rate from $61.1 \%$ with surgery alone to $71.1 \%$ with surgery plus $\mathrm{S}-1$. However, a subgroup analysis of data demonstrated that the administration of S-1 alone in patients diagnosed with stage III GC did not achieve improved survival (8). Furthermore, for metastatic or recurrent GC, a phase III trial (SPIRITS trial) comparing S-1 alone to S-1 plus cisplatin (SP) demonstrated that SP resulted in a significantly higher response rate, longer progression-free survival (PFS) and longer OS (9). As a result, there is increased acceptance of this combination therapy in China, due to the high rate of advanced gastric cancer (AGC) at presentation (1).

In comparison to cisplatin, oxaliplatin is a newer-generation platinum compound, which is less emetogenic and less nephrotoxic. Oxaliplatin may be beneficial, as it eliminates the need for pre- and post-chemotherapy hydration. Furthermore, the REAL-2 study reported that oxaliplatin was as effective as cisplatin in patients with previously untreated AGC (10). Additionally, S-1 plus oxaliplatin (SOX) was not inferior to SP regarding PFS and the treatment was shown to be well-tolerated in a randomized phase III study on AGC (11).

Oxaliplatin at $130 \mathrm{mg} / \mathrm{m}^{2}$ on day 1 , when combined with $\mathrm{S}-1$ at $80-120 \mathrm{mg} /$ day or $80 \mathrm{mg} / \mathrm{m}^{2} /$ day, was determined as the recommended dose (RD) for the treatment of colorectal cancer in phase I studies $(12,13)$ and was therefore selected for this study. In a phase I/II study of S-1 and oxaliplatin (fixed at $130 \mathrm{mg} / \mathrm{m}^{2}$ ) in AGC, the RD for a phase II study was established as $100 \mathrm{mg} / \mathrm{m}^{2}$; however, the relative dose intensity (RDI) of the S-1/oxaliplatin regimen became progressively lower over successive chemotherapy cycles (14). Considering that the typical single-agent dose of S-1, which was widely used in 
previous studies (15-18), was $80 \mathrm{mg} / \mathrm{m}^{2} /$ day, the highest dose of S-1 in the present study was set at $80 \mathrm{mg} / \mathrm{m}^{2} /$ day, with the aim of determining the maximum tolerated dose (MTD) of S-1 when administered in combination with oxaliplatin in postoperative GC patients.

FT, a vital component of $\mathrm{S}-1$, is converted to fluorouracil (FU) in the liver by the cytochrome P450 (CYP) enzymes (19). Cytochrome P450 2A6 (CYP2A6) of the CYP family is currently considered to be the principal enzyme responsible for this conversion process (20). Recent pharmacokinetic studies demonstrated that the plasma concentrations and clearances of FU and/or FT differed according to the CYP2A6 polymorphisms in patients treated with $\mathrm{S}-1(21,22)$. The alleles CYP2A6*7 and CYP2A6*10, located on exon 9 of CYP2A6, exhibited reduced activity (23-25). In this study, we assessed the polymorphic differences in the CYP2A6 gene and their impact on severe treatment toxicity.

\section{Patients and methods}

Patients. Patients with partial or total gastrectomy for previously untreated, histologically confirmed stage II/III adenocarcinoma (such as, pathological stage $\mathrm{T}_{2} \mathrm{~N}^{+}, \mathrm{T} 3-\mathrm{T} 4$ and/or $\mathrm{N}^{+}$, according to the American Joint Committee on Cancer TNM system, 7th edition) of the stomach or the gastroesophageal junction were eligible if they fulfilled the following criteria: i) age $\geq 20$ years; ii) Eastern Cooperative Oncology Group (ECOG) performance status of $0-1$; iii) absolute granulocyte count $>1,500 / \mu 1$; iv) platelet count $>100,000 / \mu \mathrm{l}$; v) hemoglobin level $>90 \mathrm{~g} / \mathrm{l}$; vi) serum bilirubin level < upper limit of normal (ULN); vii) normal creatinine level; and viii) serum glutamic-pyruvic transaminase (ALT) and glutamic-oxaloacetic transaminase (AST) levels $<1.5 X$ ULN. Patients with ascites or evidence of peritoneal, hepatic or distant metastases were excluded from this study. Only patients able to swallow tablets were considered eligible. Patients were also excluded if they had mental abnormalities, severe comorbid conditions or lacked the ability to comply. All female patients were instructed to practice medically effective contraception.

The study protocol was approved by the Ethics Committee of the Cancer Institute and Hospital, Chinese Academy of Medical Sciences and the patients provided written informed consent. This study was registered to ClinicalTrials.gov as NCT01542294.

Definitions and treatment scheme. The dose-limiting toxicity (DLT) was determined during the first treatment cycle based on the drug-related toxicity according to the National Cancer Institute Common Toxicity Criteria, version 3.0, as follows: i) $\geq$ grade 3 non-hematological toxicity (excluding controlled alopecia); ii) grade 4 hematological toxicity or febrile neutropenia; and iii) toxicity-related discontinuation of S-1 and oxaliplatin treatment for $>3$ weeks. If $\geq 2$ patients in a given cohort experienced DLT, that dose level was considered to be intolerable. The MTD was defined as the highest dose level at which $<33 \%$ of the patients experienced a DLT during the first treatment cycle. Dose-finding of S-1 was performed if no DLT was observed in a cohort of 3 patients; if DLT was observed in 1 patient, the cohort was expanded to 6 patients.
Treatment was initiated 4-8 weeks after surgery with 8 cycles of S-1/oxaliplatin combination therapy. S-1 was administered orally twice/day, within 30 mins after a meal, on days 1-14 every 3 weeks. At level 1, the dose of S-1 was $60 \mathrm{mg} / \mathrm{m}^{2}$. Subsequently, the dose of S-1 was increased by $10 \mathrm{mg} / \mathrm{m}^{2}$. The dose of S-1 was maintained if a DLT occurred and reduced if it reappeared in the subsequent cycle. Oxaliplatin was administered intravenously over $2 \mathrm{~h}$ on day 1 at a fixed dose of $130 \mathrm{mg} / \mathrm{m}^{2}$ to all the patients.

The treatment was repeated every 3 weeks. The subsequent course was initiated when the absolute neutrophil count was $\geq 1,500 / \mu 1$, the platelet count was $\geq 100,000 / \mu 1$ and non-hematological toxicities were $\leq$ grade 1 .

Evaluations during therapy. The complete blood count was monitored periodically during therapy. A full medical history with physical examination, including evaluation of the ECOG performance status (PS) and biochemistry profiles were conducted for each patient prior to each treatment cycle. The National Cancer Institute Common Toxicity Criteria, version 3.0, were used to assess toxicity.

The disease status was assessed once every 3 months on the basis of serum tumor markers and at least once every 6 months by computerised tomography scanning until the completion of 8 cycles of treatment. A self-scored daily calendar of toxicities was reviewed by each patient at the end of each cycle.

Dose modification and delays. During the first cycle of treatment, each drug was administered without intra-cycle interruption until the occurrence of DLTs. At the initiation of subsequent cycles, each drug was administered according to the dose modification method described below.

The administration of the two agents was delayed until adequate hematological recovery was achieved (absolute neutrophil count $\geq 1,500 / \mu 1$ and platelet count $\geq 100,000 / \mu 1$ ). Non-hematological toxicities, excluding alopecia, were required to be $\leq$ grade 1 prior to the initiation of each cycle. If the toxicity event did not resolve within 3 weeks following the time of planned treatment, the affected patients were withdrawn from the study.

As this study involved two agents, dose adjustments for each agent were conducted separately, if a distinction in toxicity was possible. If both agents were suspected to be responsible for the toxicity, a combined dose reduction was performed. In case of treatment-related grade 3 or 4 toxicity, S-1 was maintained and resumed at a reduced dose $\left(5 \mathrm{mg} / \mathrm{m}^{2} /\right.$ day $)$ when the toxicity had resolved and that reduced dose was used for the subsequent cycles. Oxaliplatin was reduced by $25 \%$ for the subsequent cycle in case of grade 3 or 4 toxicity. Drug doses were never increased.

The completion of the treatment was defined as follows: the patients had received $S-1$ for $\geq 14$ days per cycle, had been administered oxaliplatin and had not met the discontinuation criteria for S-1 plus oxaliplatin.

The treatment was discontinued in case of disease progression, unacceptable toxicity, completion of a full treatment protocol or according to the physician's judgement.

Genetic and statistical analyses. Blood samples were collected for isolation of genomic DNA during venipuncture 
for other diagnostic laboratory tests $\geq 1$ week prior to treatment initiation. The genotypes were determined in DNA extracted from peripheral blood samples using the QIAamp DNA Blood Mini kit (Qiagen, Valencia, CA, USA) according to the manufacturer's instructions. We analyzed the alleles CYP2A6*7 and CYP2A6*10 (containing substitutions of CYP2A6*7 and CYP2A6*8) at exon 9 of CYP2A6 by direct sequencing using forward (5'-GAA-AGA-AAT-TGA-GGC-TCA-GG-3') and reverse (5'-AGA-AGG-CTA-TGG-GCA-CAG-AT-3') primers with an ABI Prism 3730 analyzer (Applied Biosystems, Foster City, CA, USA). All primers were designed and/or validated using the Primer Express software, version 2.0 (Applied Biosystems).

In this study, we evaluated the association between CYP2A6 polymorphisms and severe toxicity throughout the entire course of the treatment, irrespective of the dose level. Each polymorphism was assessed to ensure that it fitted the Hardy-Weinberg equilibrium (HWE). The associations between categorical variables were assessed by the Fisher's exact test and included in the genotypic model. $\mathrm{P}<0.05$ was considered to indicate a statistically significant difference.

\section{Results}

Patient characteristics. A total of 15 patients (11 males and 4 females) were recruited in this study and their demographic and clinical characteristics are summarized in Table I. The median patient age was 53 years (range, 27-70 years) and the median body surface area (BSA) was $1.76 \mathrm{~m}^{2}$ (range, 1.42-2.15 $\mathrm{m}^{2}$ ). All patients exhibited a good performance status (ECOG 0-1) and were pathologically diagnosed with intestinal $(n=2)$, diffuse $(n=8)$ and mixed type adenocarcinoma $(n=5)$. Two patients had undergone radical total gastrectomy, whereas the remaining 13 patients had undergone subtotal gastrectomy. In this study, 4 patients had stage IIA disease, 3 had stage IIB, 6 had stage IIIA, 1 had stage IIIB and 1 had stage IIIC disease. None of the patients received chemotherapy in a preoperative setting.

Sequence of dose levels investigated and DLTs. The first cohort of 3 patients was initiated on level $1\left(\mathrm{~S}-1,60 \mathrm{mg} / \mathrm{m}^{2}\right.$ on days $1-14$ and oxaliplatin, $130 \mathrm{mg} / \mathrm{m}^{2}$ on day 1) and no DLTs were observed. The next cohort of 3 patients received dose level 2 (S-1, $70 \mathrm{mg} / \mathrm{m}^{2}$ on days $1-14$ and oxaliplatin, $130 \mathrm{mg} / \mathrm{m}^{2}$ on day 1). Although routine preventive antiemetic therapy had been administered, 1 patient experienced grade 3 vomiting, which constituted a DLT (Table II). We expanded the level 2 dose cohort to 6 patients and no additional DLTs occurred.

A further cohort of 3 patients were enrolled at dose level 3 (S-1, $80 \mathrm{mg} / \mathrm{m}^{2}$ administered twice daily with oxaliplatin, $\left.130 \mathrm{mg} / \mathrm{m}^{2}\right)$. One of these 3 patients experienced a DLT (grade 3 vomiting). Three further patients were added on this dose level, with one experiencing grade 3 vomiting and discontinuing the treatment due to unacceptable toxicity; this was also considered to be a DLT. Based on these results, the MTD of S-1 was initially determined to be $70 \mathrm{mg} / \mathrm{m}^{2}$.

Safety profile and treatment compliance. During the study, a total of 93 completed treatment cycles were administered, with a median of 6 (range, 1-8 treatment cycles) administered per patient. Of the 15 patients in this study, 3 (20\%) completed
Table I. Pretreatment patient characteristics.

Characteristics Patient no. $(n=15)$

\begin{tabular}{|c|c|}
\hline \multicolumn{2}{|l|}{ Age (years) } \\
\hline Median & 53 \\
\hline Range & $27-70$ \\
\hline \multicolumn{2}{|l|}{$\operatorname{BSA}\left(\mathrm{m}^{2}\right)$} \\
\hline Median & 1.76 \\
\hline Range & $1.42-2.15$ \\
\hline \multicolumn{2}{|l|}{ Gender } \\
\hline Male & 11 \\
\hline Female & 4 \\
\hline \multicolumn{2}{|l|}{ ECOG PS } \\
\hline 0 & 4 \\
\hline 1 & 11 \\
\hline \multicolumn{2}{|c|}{ Pathological type } \\
\hline Intestinal & 2 \\
\hline Diffuse & 8 \\
\hline Mixed & 5 \\
\hline \multicolumn{2}{|c|}{ Type of gastrectomy } \\
\hline Total & 2 \\
\hline Partial & 13 \\
\hline \multicolumn{2}{|l|}{ TNM stage } \\
\hline IIA & 4 \\
\hline IIB & 3 \\
\hline IIIA & 6 \\
\hline IIIB & 1 \\
\hline IIIC & 1 \\
\hline
\end{tabular}

BSA, body surface area; ECOS PS, Eastern Cooperative Oncology Group performance status.

8 cycles of the treatment plan. At the level of the MTD, the treatment was continued for $\geq 6$ cycles in all 6 patients. The adverse events are listed in Table III.

At the MTD level, chemotherapy was delayed in all 6 patients. The main reason for the delay in chemotherapy was thrombocytopenia. The level of RDI achieved for S-1 was $90-100 \%$ in $83.3 \%$ and $70-80 \%$ in $16.7 \%$ of the patients; the level of RDI for oxaliplatin was $90-100 \%$ in $83.3 \%$ and $80-90 \%$ in $16.7 \%$ of the patients.

Of the 6 patients receiving the MTD, 7 cases of grade 3 toxicity were reported in 3 patients. One patient developed grade 3 neutropenia and thrombocytopenia requiring hospitalization after the second cycle; following reduction of the S-1 and oxlaliplatin dose by $25 \%$, the patient was able to complete 6 cycles of treatment. Grade 3 neutropenia developed in one patient following the completion of 6 cycles and single-agent S-1 therapy was selected following adjustment. The remaining patient experienced grade 3 vomiting, which constituted a DLT at the MTD level.

Association of CYP2A6 polymorphisms with toxicity. We analyzed the alleles CYP2A6*7 and CYP2A6*10 (containing 
Table II. Toxicities observed at various dose levels of S-1 with oxaliplatin in 15 patients during the first treatment cycle.

\begin{tabular}{|c|c|c|c|c|c|c|c|c|c|c|c|c|}
\hline \multirow[b]{2}{*}{ Toxicity $^{\mathrm{d}}$} & \multicolumn{4}{|c|}{$60 / 130$, level $1(n=3)^{a}$} & \multicolumn{4}{|c|}{$70 / 130$, level $2(n=6)^{b}$} & \multicolumn{4}{|c|}{$80 / 130$, level $3(n=6)^{c}$} \\
\hline & $\begin{array}{c}\text { Grade } 1 \\
\text { (no.) }\end{array}$ & $\begin{array}{l}\text { Grade } 2 \\
\text { (no.) }\end{array}$ & $\begin{array}{c}\text { Grade } 3 \\
\text { (no.) }\end{array}$ & $\begin{array}{c}\text { Grade } 4 \\
\text { (no.) }\end{array}$ & $\begin{array}{c}\text { Grade } 1 \\
\text { (no.) }\end{array}$ & $\begin{array}{c}\text { Grade } 2 \\
\text { (no.) }\end{array}$ & $\begin{array}{c}\text { Grade } 3 \\
\text { (no.) }\end{array}$ & $\begin{array}{c}\text { Grade } 4 \\
\text { (no.) }\end{array}$ & $\begin{array}{c}\text { Grade } 1 \\
\text { (no.) }\end{array}$ & $\begin{array}{c}\text { Grade } 2 \\
\quad \text { (no.) }\end{array}$ & $\begin{array}{c}2 \text { Grade } 3 \\
\text { (no.) }\end{array}$ & $\begin{array}{c}\text { Grade } 4 \\
\text { (no.) }\end{array}$ \\
\hline Anemia & 1 & - & - & - & 3 & - & - & - & 1 & - & - & - \\
\hline Leukopenia & & & & & 1 & & - & - & 1 & - & - & - \\
\hline Neutropenia & 1 & - & - & - & - & 2 & - & - & 1 & - & - & - \\
\hline Thrombocytopenia & - & - & - & - & - & - & - & - & - & - & - & - \\
\hline Febrile neutropenia & - & - & - & - & - & - & - & - & - & - & - & - \\
\hline Hyperpigmentation & - & - & - & - & - & - & - & - & 2 & - & - & - \\
\hline Asthenia & - & - & - & - & 1 & - & - & - & 3 & - & - & - \\
\hline Nausea & 1 & - & - & - & 2 & 1 & - & - & 3 & 3 & - & - \\
\hline Vomiting & - & - & - & - & 1 & - & 1 & - & - & 1 & 2 & - \\
\hline Stomatitis & - & - & - & - & - & - & - & - & - & - & - & - \\
\hline Diarrhea & 1 & - & - & - & 1 & - & - & - & 1 & 3 & - & - \\
\hline Neurotoxicity & 2 & - & - & - & 1 & - & - & - & - & - & - & - \\
\hline Hand-foot syndrome & - & - & - & - & - & - & - & - & - & - & - & - \\
\hline ALT elevation & - & - & - & - & - & - & - & - & - & - & - & - \\
\hline
\end{tabular}

Table III. Toxicities during all the treatment cycles.

\begin{tabular}{|c|c|c|c|c|c|c|}
\hline \multirow[b]{2}{*}{ Toxicity $^{\mathrm{d}}$} & \multicolumn{2}{|c|}{$60 / 130$, level $1(n=3)^{a}$} & \multicolumn{2}{|c|}{$70 / 130$, level $2(n=6)^{b}$} & \multicolumn{2}{|c|}{$80 / 130$, level $3(n=6)^{c}$} \\
\hline & All grades (\%) & Grade 3/4 (\%) & All grades $(\%)$ & Grade 3/4 (\%) & All grades $(\%)$ & Grade $3 / 4(\%)$ \\
\hline Anemia & $3(100)$ & $0(0)$ & $4(66.7)$ & $0(0)$ & $2(33.3)$ & $0(0)$ \\
\hline Leukopenia & $2(66.7)$ & $0(0)$ & $4(66.7)$ & $0(0)$ & $4(66.7)$ & $2(33.3)$ \\
\hline Neutropenia & $3(100)$ & $0(0)$ & $4(66.7)$ & $2(33.3)$ & $4(66.7)$ & $1(16.7)$ \\
\hline Thrombocytopenia & $3(100)$ & $1(33.3)$ & $5(83.3)$ & $1(16.7)$ & $2(33.3)$ & $0(0)$ \\
\hline Febrile neutropenia & $0(0)$ & $0(0)$ & $0(0)$ & $0(0)$ & $0(0)$ & $0(0)$ \\
\hline Hyperpigmentation & $3(100)$ & $0(0)$ & $5(83.3)$ & $0(0)$ & $3(50)$ & $0(0)$ \\
\hline Asthenia & $3(100)$ & $0(0)$ & $5(83.3)$ & $0(0)$ & $5(83.3)$ & $0(0)$ \\
\hline Nausea & $2(66.7)$ & $0(0)$ & $4(66.7)$ & $0(0)$ & $6(100)$ & $0(0)$ \\
\hline Vomiting & $3(100)$ & $0(0)$ & $3(50)$ & $1(16.7)$ & $4(66.7)$ & $2(33.3)$ \\
\hline Stomatitis & $0(0)$ & $0(0)$ & $0(0)$ & $0(0)$ & $1(16.7)$ & $0(0)$ \\
\hline Diarrhea & $1(33.3)$ & $0(0)$ & $1(16.7)$ & $0(0)$ & $5(83.3)$ & $0(0)$ \\
\hline Neurotoxicity & $3(100)$ & $0(0)$ & $6(100)$ & $0(0)$ & $3(50)$ & $0(0)$ \\
\hline Hand-foot syndrome & $0(0)$ & $0(0)$ & $0(0)$ & $0(0)$ & $0(0)$ & $0(0)$ \\
\hline ALT elevation & $1(33.3)$ & $0(0)$ & $0(0)$ & $0(0)$ & $2(33.3)$ & $0(0)$ \\
\hline
\end{tabular}

${ }^{\mathrm{a}} \mathrm{S}-1,60 \mathrm{mg} / \mathrm{m}^{2}$ on days $1-14$ and oxaliplatin, $130 \mathrm{mg} / \mathrm{m}^{2}$ on day $1 .{ }^{\mathrm{b}} \mathrm{S}-1,70 \mathrm{mg} / \mathrm{m}^{2}$ on days $1-14$ and oxaliplatin, $130 \mathrm{mg} / \mathrm{m}^{2} \mathrm{on}$ day $1 .{ }^{\mathrm{c}} \mathrm{S}-1$,

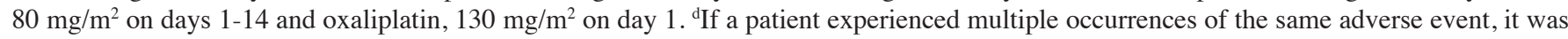
registered with the highest grade/severity. ALT, serum glutamic-pyruvic transaminase (SGPT).

substitutions of CYP2A6*7 and CYP2A6*8), which resulted in reduced enzyme activity. All the variants were in HWE. The variant allelic frequencies were 0.33 for CYP2A6*7, 0.27 for CYP2A6*8 and 0.10 for CYP2A6*10. The two polymorphisms were not significantly associated with severe grade 3 or 4 toxicity during the entire course of the treatment (Table IV).

However, we identified a variant in the vicinity, CYP2A6 41349640C > G (rs7248240), with frequencies of 0.73 and 0.27 for the $\mathrm{C}$ and $\mathrm{G}$ alleles, respectively. CYP2A6 41349640C>G 
Table IV. Univariate analysis of the association between CYP2A6 polymorphisms and severe toxicity during the entire course of the treatment.

\begin{tabular}{|c|c|c|c|c|c|c|c|c|c|}
\hline \multirow[b]{2}{*}{ Polymorphism } & \multicolumn{3}{|c|}{ Neutropenia } & \multicolumn{3}{|c|}{ Hematological } & \multicolumn{3}{|c|}{ Vomiting } \\
\hline & No. ${ }^{a}$ & $\%$ & P-value ${ }^{b}$ & No. ${ }^{a}$ & $\%$ & P-value & No. ${ }^{a}$ & $\%$ & P-value \\
\hline \multicolumn{10}{|c|}{ CYP2A6 $41349640 \mathrm{C}>\mathrm{G}$} \\
\hline $\mathrm{C} / \mathrm{C}$ & 0 of 8 & 0 & 0.03297 & 1 of 8 & 12.50 & 0.1422 & 2 of 8 & 25 & 1 \\
\hline $\mathrm{C} / \mathrm{G}$ & 2 of 6 & 33.33 & - & 3 of 6 & 50 & - & 1 of 6 & 16.67 & - \\
\hline $\mathrm{G} / \mathrm{G}$ & 1 of 1 & 100 & - & 1 of 1 & 100 & - & 0 of 1 & 0 & - \\
\hline \multicolumn{10}{|l|}{ CYP2A6*8 } \\
\hline $\mathrm{C} / \mathrm{C}$ & 3 of 10 & 30 & 0.51650 & 4 of 10 & 40 & 1 & 1 of 10 & 10 & 0.1538 \\
\hline $\mathrm{C} / \mathrm{A}$ & 0 of 5 & 0 & - & 1 of 5 & 20 & - & 2 of 5 & 40 & - \\
\hline $\mathrm{A} / \mathrm{A}$ & 0 of 0 & 0 & - & 0 of 0 & 0 & - & 0 of 0 & 0 & - \\
\hline \multicolumn{10}{|l|}{ CYP2A6*7 } \\
\hline $\mathrm{A} / \mathrm{A}$ & 2 of 10 & 20 & 1 & 3 of 10 & 30 & 1 & 2 of 10 & 20 & 1 \\
\hline $\mathrm{A} / \mathrm{G}$ & 1 of 5 & 20 & - & 2 of 5 & 40 & - & 1 of 5 & 20 & - \\
\hline $\mathrm{G} / \mathrm{G}$ & 0 of 0 & 0 & - & 0 of 0 & 0 & - & 0 of 0 & 0 & - \\
\hline \multicolumn{10}{|l|}{ CYP2A6*10 } \\
\hline $\mathrm{W} / \mathrm{W}$ & 3 of 12 & 25 & 1 & 4 of 12 & 33.33 & 1 & 2 of 12 & 16.67 & 0.5165 \\
\hline $\mathrm{W} / \mathrm{V}$ & 0 of 3 & 0 & - & 1 of 3 & 33.33 & - & 1 of 3 & 33.33 & - \\
\hline $\mathrm{V} / \mathrm{V}$ & 0 of 0 & 0 & - & 0 of 0 & 0 & - & 0 of 0 & 0 & - \\
\hline
\end{tabular}

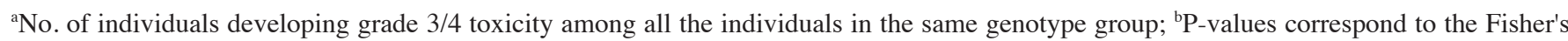
exact test and are included in the genotypic model. CYP2A6, cytochrome P450 2A6; V, variant allele of CYP2A6*7 and CYP2A6*8; W, wild-type allele of CYP2A6*7 and CYP2A6*8.

was associated with severe neutropenia (C/C vs. $\mathrm{C} / \mathrm{G}$ vs. $\mathrm{G} / \mathrm{G}=0$ vs. 33.33 vs. $100 \% ; \mathrm{P}=0.03297$, Fisher's exact test) during the entire course of the treatment. Patients with the $\mathrm{C} / \mathrm{G}$ or $\mathrm{G} / \mathrm{G}$ genotype tended to have a higher incidence of grade 3 or 4 neutropenia compared to those with the $\mathrm{C} / \mathrm{C}$ genotype.

\section{Discussion}

To the best of our knowledge, this is the first dose-finding study of S-1/oxaliplatin combination adjuvant chemotherapy for the treatment of GC. At the established MTD of SOX, the $\mathrm{S}-1$ dose $\left(70 \mathrm{mg} / \mathrm{m}^{2} /\right.$ day) was lower in our study compared to that used in previous studies ( $80 \mathrm{mg} / \mathrm{m}^{2} /$ day) $(15-18)$. At the MTD level, the predominant grade 3/4 toxicities observed in patients included neutropenia $(33.3 \%)$, thrombocytopenia (16.7\%) and vomiting (16.7\%). Treatment was continued for $\geq 6$ cycles in all 6 patients, with a RDI level of $>90 \%$ for $\mathrm{S}-1$ and oxaliplatin achieved in $83.3 \%$ of the patients. The treatment was well-tolerated and the toxicity profile was considered acceptable, which were shown to be key factors against GC.

During the present study, three events of DLT (grade 3 vomiting) were observed. It was hypothesized that both agents contributed to the DLTs. Of the 15 patients included in this study, 16 cases of grade 3 toxicity were reported in 8 patients, whereas neutropenia ( 7 cases) and vomiting (5 cases) were frequent findings. Grade 3 vomiting was observed in one case at level 2 and in two cases at level 3, highlighting the fact that S-1 plays an important role in DLT. Total gastrectomy significantly increased the maximum concentration and the areas under the curves of plasma FU and CDHP following the administration of S-1, which has been reported in several studies regarding S-1 pharmacokinetics following gastrectomy $(26,27)$, which may be another explanation for the DLTs. However, the exact cause of the high incidence of grade 3 vomiting during the first treatment cycle was undetermined, possibly due to the small sample size and a lack of pharmacokinetic experiments.

In the present study, we observed no significant association of the alleles CYP2A6*7, CYP2A6*8 or CYP2A6*10 with severe toxicity (Table IV). Compared with the significant association with tumour response rates and OS $(28,29)$, one possible explanation is that Oxo inhibits the phosphorylation of $\mathrm{FU}$ in the gastrointestinal tract, thereby reducing the gastrointestinal toxic effects of FU and the effect of CYP2A6 on severe toxicity.

However, we observed that CYP2A6 41349640C $>$ G (rs7248240), a variant located in the vicinity, was associated with severe neutropenia (C/C vs. $\mathrm{C} / \mathrm{G}$ vs. $\mathrm{G} / \mathrm{G}=0$ vs. 33.33 vs. $100 \%$; $\mathrm{P}=0.03297$, Fisher's exact test) during the course of treatment. This polymorphism was located in the $3^{\prime}$ untranslated region (3' UTR) of CYP2A6. Heterogeneous nuclear ribonucleoprotein (hnRNP) A1, a critical regulator of human CYP2A6 gene expression, exhibits modified binding characteristics to the CYP2A6 3' UTR compared with the primary hepatocytes $(30,31)$. These results indicate that the single-nucleotide substitution of $C \rightarrow G$ at position 41349640 may decrease the ability of hnRNP A1 to bind to the 3' UTR of CYP2A6 and reduce the expression levels of the CYP2A6 gene, eventually leading to severe toxicity.

In conclusion, the MTD of S-1, when administered in combination with oxaliplatin in Chinese postoperative 
GC patients, was determined to be $70 \mathrm{mg} / \mathrm{m}^{2}$ twice daily on days $1-14$, with $130 \mathrm{mg} / \mathrm{m}^{2}$ oxaliplatin on day 1 , every 21 days.

\section{Acknowledgements}

S-1 was kindly provided by Taiho Pharmaceutical Company (Tokyo, Japan).

\section{References}

1. Kamangar F, Dores GM and Anderson WF: Patterns of cancer incidence, mortality, and prevalence across five continents: defining priorities to reduce cancer disparities in different geographic regions of the world. J Clin Oncol 24: 2137-2150, 2006.

2. Parkin DM, Bray F, Ferlay J and Pisani P: Global cancer statistics, 2002. CA Cancer J Clin 55: 74-108, 2005.

3. Cunningham D, Allum WH, Stenning SP, Thompson JN, Van de Velde CJ, Nicolson M, Scarffe JH, Lofts FJ, Falk SJ, Iveson TJ, Smith DB, Langley RE, Verma M, Weeden S, Chua YJ, MAGIC Trial Participants: Perioperative chemotherapy versus surgery alone for resectable gastroesophageal cancer. N Engl J Med 355: 11-20, 2006.

4. Macdonald JS, Smalley SR, Benedetti J, Hundahl SA, Estes NC, Stemmermann GN, Haller DG, Ajani JA, Gunderson LL, Jessup JM and Martenson JA: Chemoradiotherapy after surgery compared with surgery alone for adenocarcinoma of the stomach or gastroesophageal junction. N Engl J Med 345: 725-730, 2001.

5. Chollet P, Schöffski P, Weigang-Köhler K, Schellens JH, Cure H, Pavlidis N, Grünwald V, De Boer R, Wanders J and Fumoleau P, EORTC Early Clinical Studies Group: Phase II trial with S-1 in chemotherapy-naïve patients with gastric cancer. A trial performed by the EORTC Early Clinical Studies Group (ECSG). Eur J Cancer 39: 1264-1270, 2003.

6. Koizumi W, Kurihara M, Nakano S and Hasegawa K: Phase II study of S-1, a novel oral derivative of 5-fluorouracil, in advanced gastric cancer. For the S-1 Cooperative Gastric Cancer Study Group. Oncology 58: 191-197, 2000

7. Sakata Y, Ohtsu A, Horikoshi N, Sugimachi K, Mitachi Y and Taguchi T: Late phase II study of novel oral fluoropyrimidine anticancer drug S-1 (1 M tegafur- $0.4 \mathrm{M}$ gimestat-1 M otastat potassium) in advanced gastric cancer patients. Eur J Cancer 34 1715-1720, 1998

8. Sasako M, Sakuramoto S, Katai H, Kinoshita T, Furukawa H, Yamaguchi T, Nashimoto A, Fujii M, Nakajima T and Ohashi Y: Five-year outcomes of a randomized phase III trial comparing adjuvant chemotherapy with S-1 versus surgery alone in stage II or III gastric cancer. J Clin Oncol 29: 4387-4393, 2011.

9. Koizumi W, Narahara H, Hara T, et al: S-1 plus cisplatin versus S-1 alone for first-line treatment of advanced gastric cancer (SPIRITS trial): a phase III trial. Lancet Oncol 9: 215-221, 2008.

10. Cunningham D, Starling N, Rao S, Iveson T, Nicolson M, Coxon F, Middleton G, Daniel F, Oates J and Norman AR; Upper Gastrointestinal Clinical Studies Group of the National Cancer Research Institute of the United Kingdom: Capecitabine and oxaliplatin for advanced esophagogastric cancer. N Engl J Med 358: 36-46, 2008.

11. Higuchi K, Koizumi W, Yamada Y, et al: Randomized phase III study of S-1 plus oxaliplatin versus S-1 plus cisplatin for first-line treatment of advanced gastric cancer. J Clin Oncol 30 (Suppl 34; abs. 60), 2012

12. Li J, Yin J, Zhu X, Liu Y, Cao J, Lu F and Zuo Y: Phase I dose-escalating study of S-1 in combination with oxaliplatin for patients with advanced and/or metastatic colorectal cancer. Anticancer Drugs 19: 745-748, 2008.

13. Yamada Y, Tahara M, Miya T, Satoh T, Shirao K, Shimada Y, Ohtsu A, Sasaki Y and Tanigawara Y: Phase I/II study of oxaliplatin with oral S-1 as first-line therapy for patients with metastatic colorectal cancer. Br J Cancer 98: 1034-1038, 2008.
14. Park I, Lee JL, Ryu MH, et al: Phase I/II and pharmacokinetic study of S-1 and oxaliplatin in previously untreated advanced gastric cancer. Cancer Chemother Pharmacol 65: 473-480, 2010

15. Kim GM, Jeung HC, Rha SY, Kim HS, Jung I, Nam BH, Lee KH and Chung HC: A randomized phase II trial of S-1-oxaliplatin versus capecitabine-oxaliplatin in advanced gastric cancer. Eur J Cancer 48: 518-526, 2012.

16. Kodera Y, Ito S, Mochizuki Y, et al; Chubu Clinical Oncology Group: A phase II study of radical surgery followed by postoperative chemotherapy with S-1 for gastric carcinoma with free cancer cells in the peritoneal cavity (CCOG0301 study). Eur J Surg Oncol 35: 1158-1163, 2009.

17. Liu B, Ying J, Luo C, Xu Q, Zhu L and Zhong H: S-1 combined with oxaliplatin as first line chemotherapy for Chinese advanced gastric cancer patients. Hepatogastroenterology 59: 649-653, 2012.

18. Yoshikawa T, Omura K, Kobayashi O, Nashimoto A, Takabayashi A, Yamada T, Yamaue H, Fujii M, Yamaguchi T and Nakajima T: A phase II study of preoperative chemotherapy with S-1 plus cisplatin followed by D2/D3 gastrectomy for clinically serosa-positive gastric cancer (JACCRO GC-01 study). Eur J Surg Oncol 36: 546-551, 2010.

19. El Sayed YM and Sadee W: Metabolic activation of ftorafur [R,S-1-(tetrahydro-2-furanyl)-5-fluorouracil]: the microsomal oxidative pathway. Biochem Pharmacol 31: 3006-3008, 1982.

20. Ikeda K, Yoshisue K, Matsushima E, Nagayama S, Kobayashi K, Tyson CA, Chiba K and Kawaguchi Y: Bioactivation of tegafur to 5-fluorouracil is catalyzed by cytochrome P-450 2A6 in human liver microsomes in vitro. Clin Cancer Res 6: 4409-4415, 2000.

21. Fujita K, Yamamoto W, Endo S, et al: CYP2A6 and the plasma level of 5-chloro-2,4-dihydroxypyridine are determinants of the pharmacokinetic variability of tegafur and 5-fluorouracil, respectively, in Japanese patients with cancer given S-1. Cancer Sci 99: 1049-1054, 2008.

22. Kim KP, Jang G, Hong YS, et al: Phase II study of S-1 combined with oxaliplatin as therapy for patients with metastatic biliary tract cancer: influence of the CYP2A6 polymorphism on pharmacokinetics and clinical activity. Br J Cancer 104: 605-612, 2011.

23. Ariyoshi N, Sawamura Y and Kamataki T: A novel single nucleotide polymorphism altering stability and activity of CYP2a6. Biochem Biophys Res Commun 281: 810-814, 2001.

24. Xu C, Rao YS, Xu B, Hoffmann E, Jones J, Sellers EM and Tyndale RF: An in vivo pilot study characterizing the new CYP2A6*7, *8, and $* 10$ alleles. Biochem Biophys Res Commun 290: 318-324, 2002.

25. Yoshida R, Nakajima M, Watanabe Y, Kwon JT and Yokoi T: Genetic polymorphisms in human CYP2A6 gene causing impaired nicotine metabolism. Br J Clin Pharmacol 54: 511-517, 2002.

26. Kim WY, Nakata B and Hirakawa K: Alternative pharmacokinetics of S-1 components, 5-fluorouracil, dihydrofluorouracil and alpha-fluoro-beta-alanine after oral administration of S-1 following total gastrectomy. Cancer Sci 98: 1604-1608, 2007.

27. Kochi M, Fujii M, Kanamori N, Kaiga T, Aizaki K, Takahashi T and Takayama T: Effect of gastrectomy on the pharmacokinetics of S-1, an oral fluoropyrimidine, in resectable gastric cancer patients. Cancer Chemother Pharmacol 60: 693-701, 2007.

28. Kong SY, Lim HS, Nam BH, et al: Association of CYP2A6 polymorphisms with S-1 plus docetaxel therapy outcomes in metastatic gastric cancer. Pharmacogenomics 10: 1147-1155, 2009.

29. Park SR, Kong SY, Nam BH, et al: CYP2A6 and ERCC1 polymorphisms correlate with efficacy of S-1 plus cisplatin in metastatic gastric cancer patients. Br J Cancer 104: 1126-1134, 2011.

30. Christian K, Lang M, Maurel P and Raffalli-Mathieu F: Interaction of heterogeneous nuclear ribonucleoprotein A1 with cytochrome P450 2A6 mRNA: implications for post-transcriptional regulation of the CYP2A6 gene. Mol Pharmacol 65: 1405-1414, 2004

31. Raffalli-Mathieu F, Glisovic T, Ben-David Y and Lang MA: Heterogeneous nuclear ribonucleoprotein A1 and regulation of the xenobiotic-inducible gene Cyp2a5. Mol Pharmacol 61: 795-799, 2002. 